\title{
Social Capital and the U.S. College Experiences of International Student-Athletes and Non-Athletes
}

\author{
Helen Forbes-Mewett \\ Monash University, Australia \\ Madeleine Pape \\ Northwestern University, USA
}

\begin{abstract}
This study shifts the tendency to focus on international students' negative experiences of undertaking education in a host country to a group that enjoys an elevated level of support. By looking at international student-athletes compared with non-athletes, it is shown how the former group experiences the benefits of social capital. Insights relating to international student-athletes in the US reveal strong and ongoing support from coaches and teammates. It is shown that international student-athletes have far greater support structures compared with international non-athletes. In doing so, this study presents a new perspective to debates on what higher education institutions in host countries can do to support their international student populations.
\end{abstract}

Keywords: athletes, college, international students, social capital, student experience

International students tend to be associated with host country economic gain as well as vulnerability in terms of their safety and security. Research to date concerning the international student experience has focused primarily on their vulnerability, especially the challenges faced by large numbers of students from China and India (Marginson, Nyland, Sawir, \& Forbes-Mewett, 2010). Australian studies have tended to be at micro and meso levels, and have looked at international student security broadly to include housing, employment, finances, English language difficulties, and safety (Forbes-Mewett, Marginson, Nyland, Ramia, \& Sawir, 2009; Marginson et al., 2010). More recently in the United Kingdom, the focus has been on offering a safer study destination, with pointed reference to the violence against Indian students in Australia in 2009 (British Council, 2012). However, international students are a heterogeneous population, and we know little about the experiences of those in more 
privileged situations. In short, studies of international students have tended to "study down" rather than "study up" (Sprague, 2005, p. 11) and our knowledge of their experiences has been limited primarily to those that we associate with vulnerability and victimhood. Given these social statuses provide associated perspectives, much can be learned about processes of marginalization by turning our analytical attention to the construction of privilege (Hastie \& Rimmington, 2014; Lewis, 2004).

This study represents a significant shift from a previous focus on negative aspects of undertaking education in a host country. By contrast, our study considers notions of privilege by investigating the production of social capital across diverse groups of international students - that is, the development of network ties enabling the realization of beneficial outcomes. It seeks to understand what it is like to live and study in the US for international student-athletes, in this instance sampled from the sport of track-and-field and primarily the top division of collegiate competition, compared with non-athlete international students from various countries. Here we use the term "athlete" to refer to those engaged in varsity sport, while recognizing that those students we designate "non-athletes" may nonetheless be engaged in other forms of sport or have an athletic background (see Lubker \& Etzel, 2007). Use of the term "athlete" also denotes a formal relationship to the U.S. collegiate sport system. Studying this population adds a new dimension to the literature that examines international student well-being. Furthermore, it shows that social capital in the form of social connections and support is unevenly spread across different student groups. That is, contrary to claims that international student groups are generally lacking in support (Marginson et al., 2010), the international student-athletes in this study were evidenced to be better supported than their non-athlete counterparts.

The concept of social capital has been used to understand how the social networks of student-athletes differ from those of the non-athlete population, with implications for their academic success and wellbeing (Clopton, 2010). Studentathletes are generally considered to experience a unique sense of community and stronger social networks than their non-athlete peers, largely because of the frequency and intensity of their interactions with teammates and coaching staff (Wolf-Wendel, Toma, \& Morphew, 2001). Furthermore, it seems that sports participation in general enhances social capital development by strengthening an individual's connection with their broader social environment (Perks, 2007). Yet scholars have also documented the exclusionary and divisive tendencies of sport (Elling \& Claringbould, 2005). The present study is situated at the intersection of college sports and international education, two institutional spheres that shape and are shaped by relations of social capital, in comparing international student-athletes with their nonathlete counterparts. We aim to find links between the micro and meso level experiences of the participants and macro-level institutional processes.

We argue that despite their status as non-citizens and regardless of division, international student-athletes living and studying in the US are in a position of privilege due to the institutional arrangements that attribute social capital to U.S. collegiate sports. Because of this privilege, they are shielded from many of the challenges typically faced by international students (see Forbes-Mewett, McCulloch, $\&$ Nyland, 2015; Marginson et al., 2010). This situation leads us to question: What do the experiences of these student-athletes reveal about stratification in higher 
education institutions, and what can be done to improve circumstances for other international students who find themselves without adequate support?

In pursuing these questions, this article contributes a new perspective to debates on what higher education institutions in host countries can do to recognize, integrate, and protect their heterogeneous international student populations. It also provides a deeper understanding of the social and institutional ties that can enable international students to succeed in a foreign environment. While it has been acknowledged that international students in the United States generally enjoy a positive experience (Forbes-Mewett et al., 2015), our analysis suggests that they typically experience a level of social capital that is second to that of international student-athletes. In what follows, we review the concept of social capital as embedded within the practices and structures of institutions. We then describe college sport as a source of stratification within the institution of higher education in the US. Following the analysis of our empirical material, we conclude by suggesting how the experiences of international student-athletes point to clear ways that administrators can improve the generic support currently provided to international students. We argue that both groups of international students would benefit from targeted efforts to increase the diversity of their social networks.

\section{THEORETICAL CONTEXT}

\section{A Social Capital Framework}

We opt for a social capital framework that highlights the relationship between social structure and individual capacity to act, bringing attention and analytical specificity to the enabling and disabling effects of intra- and intergroup networks (Woolcock \& Narayan, 2000). The concept of social capital is widely used within studies of educational attainment, migrant communities, and sports (see Coleman, 1988). We draw on Coleman's (1988) notion of social capital as:

...defined by its function. It is not a single entity but a variety of different entities, with two elements in common: they all consist of some aspect of social structures, and they facilitate certain actions of actors ... within the structure. (p. 98, emphasis added)

Bourdieu (1986) similarly defined social capital as the "aggregate of the actual or potential resources which are linked to possession of a durable network or more or less institutionalized relationships or recognition" (p. 248, emphasis added). Thus, both Coleman and Bourdieu emphasized social capital as the benefits that accrue to individuals through their ties with others, and particularly because of their embeddedness not only within certain communities but also broader institutions (see also Portes, 2000).

Moreover, social capital is a function of relationships rather than an attribute of individual agents themselves (Schuller, Baron, \& Field, 2000). We also draw on Putnam's (2000) association of social capital with both intra- and intercommunity networks. Putnam suggested that social capital performs a "bonding" function when it enhances or strengthens relations within a social group. It can also play a "bridging" 
role within social relationships that extend beyond immediate community boundaries. We suggest that both intra- and intergroup ties are important in shaping an individual student's opportunity structure (see also Rose-Redwood \& Rose-Redwood, 2013).

The relations that produce social capital include those between individuals and communities, but can also be extended to encompass the role of overarching social institutions. Scholars have used the concept of "linking" social capital to describe the enabling and disabling effects of the vertical relations between individuals and these institutions (Woolcock \& Narayan, 2000). Ranson's (2012) work on schools and civil society notes that leadership of institutions "endeavoured to accumulate social capital by appointing governors who bring their networks of information, knowledge and resource contacts to enrich the practice of a school" (p. 40, original emphasis). Thus, Ranson conceptualized education as an institutional sphere that mediates social capital by linking individual capacity to act to broader structures of inequality.

We adopt what we term a "critical institutional approach" to social capital, in that we examine how the relations institutionalized within higher education facilitate the generation of social capital but do so unevenly. Here the purpose is to identify how the specific institutional mechanisms that distribute social capital intersect with the schemas of inequality that stratify higher education, in this case in the U.S. context. As noted by others, social capital is inseparable from institutionalized forms of inequality that shape experience at different social locations (Das, 2004). As such, the institutionalized conditions for social capital realization may support hostile and discriminatory forms of exclusion (Field, 2003). The experiences of international students and student-athletes, therefore, should reflect their heterogeneous relations to a range of institutions, including higher education, migration, and sports.

\section{Institutions and Social Capital: Migration, International Education, and Sport}

Scholars have argued that social capital is a valuable resource for migrant communities (Jacobs \& Tillie, 2004) and the experiences of international students have been likened to those of newly arriving immigrants (Neri \& Ville, 2008). Indeed, in the case of international students, crossing international borders to pursue higher education presents many challenges frequently involving culture shock and is characterized by anxiety, loneliness, disorientation, alienation, and homesickness (Forbes-Mewett, McCulloch, \& Nyland, 2015; Forbes-Mewett \& Nyland, 2008; Marginson et al., 2010; Neri \& Ville 2008; Ward, Bochner, \& Furnham, 2001).

Existing research suggests that the institutional and social location of international students impacts their capacity to adapt to their new environment, and that this process can be understood in terms of social capital (Hendrickson, Rosen, \& Aune, 2011; Rose-Redwood \& Rose-Redwood, 2013). For example, Lee and Rice (2007) found that international students in the US experience feelings of discomfort and alienation when ignored in the classroom or excluded from social events by other students. They argued further that "negotiating basic academic procedures and living arrangements are daunting tasks for some international students" (2007, p. 6). In the Australian context, Neri and Ville (2008) found that in comparison with their domestic peers, international students may struggle to benefit from orientation programs, understand course material, obtain high grades, and contribute to class 
discussion. Existing university support systems are often inadequate as a means of helping international students adapt to their new social and educational environments (Cho \& Yu, 2015; Forbes-Mewett \& Nyland, 2013; Forbes-Mewett \& Sawyer, 2016).

However, social networks developed through involvement in clubs and paid employment contributed to the wellbeing of international students who rarely "forged relationships with domestic students or in the local community that might have provided them with insights into the broader culture" (Neri \& Ville, 2008, p. 33). Instead they tended to form networks with students from their own country of origin, suggesting that some international students can more readily develop bonding rather than bridging social capital. Moreover, Neri and Ville found that "students from Western countries do better than those from non-Western countries" (p. 35). Overall, research suggests that international students face an uneven institutional terrain marked by the racialized ideologies of the broader social context in their host nation (Marginson et al., 2010; Neri \& Ville, 2008). University administrators can counter this unevenness by intentionally creating the conditions for interaction among students from different national and cultural backgrounds (Rienties \& Nolan, 2014).

\section{Heterogeneity and the Student-Athlete Experience}

Intercollegiate sport in the US, which is governed by the National Collegiate Athletic Association (NCAA), has been described as "American higher education's 'peculiar institution"” (Thelin, 1994, p. 1). According to Harrison et al. (2009, p. 79), student-athletes are a "nontraditional' group on campus because of their relationship to the complex 'social and political system of college sport'." Indeed, they face a unique combination of academic, sporting, and social pressures (Etzel, Watson, Visek, \& Maniar, 2006). However, the institutional authority of sports in U.S. college life is also such that student-athletes are often located within privileged social networks, with access to unique support services, especially at the Division I level (Potuto \& O'Hanlon, 2007). Nevertheless, a key criticism here is that the extensive support programs provided to student-athletes inadvertently contribute to their social and academic segregation within the broader student community (Bowen \& Levin, 2003). Moreover, it is unclear whether the institutional and cultural privileges and associated social capital enjoyed by student-athletes afford them positive social and academic benefits (Gayles, 2009). On the one hand, Clopton (2010) found that student-athletes identify with their university at a far greater level than their nonathlete counterparts. Scholars have also shown that student-athletes are more academically engaged and have a higher rate of graduation than non-athletes (Ferris, Finster, \& McDonald, 2004). On the other hand, some scholars have shown that student-athletes experience less academic success and develop lower academic and career aspirations than their non-athlete peers because of the demands imposed by their sport-focused, competitive environment (Comeaux \& Harrison, 2011). Other research suggests considerable overlap in the college experiences of student-athletes and non-athletes (Umbach, Palmer, Kuh, \& Hannah,, 2006). These mixed results justify subgroup analyses to better understand the factors shaping social capital realization among athletes and non-athletes. In our study, we explore how these structural factors vary in the case of international student-athletes and non-athletes. 


\section{International Student-Athletes as High Achievers}

Efforts to recruit international student-athletes have been critiqued for diminishing the number of scholarships available to U.S. citizens and encouraging elitism among NCAA institutions (Ridinger \& Pastore, 2000). Despite their elite status and trajectory, international student-athletes are more likely than their domestic peers to view academic achievement as a central goal (Bale, 1991). They typically arrive in the US well prepared and experience fewer of the academic challenges encountered by some domestic student-athletes. Nevertheless, international studentathletes may return home prior to completing their degree because of the challenge of adjusting to life at a U.S. college (Popp, Love, Kim, \& Hums, 2010). Similar to the non-athlete international student population, the three greatest challenges for international student-athletes are homesickness, adjustment to U.S. culture, and language (Pierce, Popp, \& Meadows, 2011). However, with the addition of resources available to student-athletes (Ridinger \& Pastore, 2000), this seemingly elite group provides a new perspective for the literature pertaining to supporting international students' success.

\section{METHODS}

Using in-depth interviews, we assessed the extent to which the two groups access and feel supported by university services and mentors (linking social capital) and compared the depth and composition of their friendship networks (bonding and bridging social capital). Rather than adopting the full conceptual model of Comeaux and Harrison (2011) to analyze the multiple stages of student-athlete development, we focused on two stages in the international student sojourn: initial support upon arrival and day-to-day support throughout the remainder of their stay. Interview questions were broad and addressed general wellbeing and available support services.

\section{Research Participants}

Our sample of 25 international students from multiple U.S. colleges was purposively drawn from a larger cross-national study across three countries (ForbesMewett et al., 2015). A snowballing approach was used for original recruitment. All participants were provided with an explanatory statement about the study including details of approval from the Monash University Standing Committee on Ethics in Research on Humans. Participants signed informed consent forms. Of the sample, 19 were actively studying in the U.S. context and six had completed their studies in the US within the previous 3 years. The 12 international student-athletes included an equal number of male- and female-identifying participants, all of whom were from a single country and one team sport. Ten of these attended Division I schools, and all were receiving scholarships to cover their tuition, accommodations, and food expenses. The 13 non-athlete international students were aged 20-32 and included eight men and five females. Their countries of origin were diverse and included Australia, China, Germany, India, Malaysia, Poland, and Turkey. In this regard, our sample reflects the globalized nature of higher education. At the same time, and 
reflecting our exploratory qualitative approach, we do not claim to have representative samples of international students or student-athletes. While this approach means we cannot measure broad and generalizable patterns in the experiences of these two groups of students, our sample does support an in-depth exploration of the ways in which our interviewees relate to their institutional environment. In the findings that follow, all interviewees are described in terms of their gender and their status as student-athletes or non-athletes. We identify all participants by gender and age, but to preserve confidentiality for the student-athletes in our sample, only the non-athletes are identified by nationality.

\section{Data Collection and Analytic Approach}

The in-depth and semi-structured interviews were conducted face-to-face or over the phone. They ranged from 40-60 min, addressing topics related to the international student experience including orientation, ongoing student services, safety and security, financial support, academic support, friendship networks, and other support networks. Questions included: Were you greeted on arrival at the airport? Was your accommodation arranged? Did you know anyone before arriving at the host institution? Who do you turn to in times of need? A limitation of our reliance on interviews was that students may have reported socially desirable behavior (Yee, 2016). However, since this limitation was likely across both athletes and non-athletes, it does not compromise our goal of comparison.

Interviews were recorded and later transcribed. Both authors served as interviewers and wrote memos after each interview to record and share emerging themes, ideas, and questions (Strauss \& Corbin, 1990). The focus on social capital followed our initial immersion in the data and subsequent iterative coding approach. We read and re-read the transcripts to identify emergent themes and generate overarching categories, consistent with Strauss and Corbin's (1990) description of open and axial coding. Both authors conducted coding independently while regularly comparing and refining common overarching themes and categories. We also compared and discussed our application of these themes and categories to the interview data to reach agreement on how to interpret and represent it. In presenting the data below, our approach was to emphasize participants' voices so that the focus was drawn to students' lived experiences (Parry, McLeod, Hockings, \& Kenway, 2011).

\section{RESULTS}

Our findings are organized in two sections, corresponding chronologically with the two stages of the international student experience noted above: arrival and corresponding initial support, and the regular period of their sojourn following initial orientation, characterized by day-to-day support systems and services. Over these two periods we identified key differences in the institutionalized means available to the two groups of students to develop their social capital, which relate to proximity to institutional support, access to authority figures, and extent of organized interactions with peers and other student populations. 


\section{Initial Support: Airport Welcomes and Ready-Made Networks}

Our interviews revealed that the support provided upon arrival was two-tiered as it was characterized by very different institutional relationships. Most interview participants and particularly student-athletes responded positively to questions regarding initial support upon arrival in the US and early stages of their sojourn. The international student-athletes in our sample found the arrival experience to be extremely welcoming. Almost all student-athletes reported that they were met at the airport by their coach or a teammate. For example: "From the first time I arrived they were really good. Especially being an international [athlete] ... they'd arranged one of the team members to pick me up" (female, 23). Coaches often greeted international student-athletes on their arrival:

... for the head coach to come out and greet you ... it's a big deal. ... It was late at night and he showed me around the campus and we had a meal together and discussed a few things. ... Yeah, he did make me very welcome. (male, 18)

The welcoming process often extended from the airport pick-up to assisting the student-athletes with initial tasks, including in one case staying at the team manager's home for the first few nights. Interviewees frequently mentioned being escorted on shopping trips to purchase essential items and to offices on campus to sort paper work and class details. According to one student-athlete, "[they] got us bedding and towels and all the necessities we need ... they make it very easy for us" (female, 26). In another example, the student-athlete explained:

The coach took me round for the next three days [after arriving], just helping me get to know the area a bit, taking me around campus ... helping [with] documentation, sorting through all my classes ... [introducing] all the people that I might need to speak to if I needed help, and then gave me a tour of all the athletic facilities. (male, 19)

However, while student-athletes in the US received institutionalized support upon arrival, when such support did exist for non-athletes, it was provided by less institutionally embedded student-run organizations. Nevertheless, such support was perceived favorably. According to one Chinese international student (non-athlete) in our sample:

A general welcoming environment was created here. I honestly don't remember having anything similar when I arrived in the UK, in Nottingham. ... Here [in the US], we have the Chinese Student and Scholars Association that basically provides airport pickup service when you first arrive here. ... It was very welcoming. (male, 21)

Interviewees also generally reported positively on the period following their arrival, particularly student-athletes. Comments ranged from administrative enrollment procedures, "[My enrollment] was already done when I got here" (female, 26) to assistance with banking: "they set us up with the local [American] bank here so I can deposit money and withdraw without having to pay the charges associated 
with an international card" (female, 20). In addition to the support provided by coaches, there was also evidence of strong ties and support mechanisms between the student-athletes: "When you first come here you've already got an immediate group of friends, the guys that you're on the team with, whereas if I came here and I didn't have a team ... I would need to make friends in class" (female, 20).

Indeed, most student-athletes felt prepared for their sojourn before arrival in the US and often knew other student-athletes at their destination, sometimes via social media. For example:

With Facebook, you've basically met everyone before you got there, we ... knew what everyone looked like, what [they were] into and where they were from ... I'd been there to visit before I went over as well so ... I had met basically all the other girls. (female, 22)

Being part of a varsity team provided comfort in unfamiliar surroundings and ready access to established resources for the development of social capital. This advantage was further assisted through social media as a vehicle for social capital, highlighting the generational shifts in network formation brought about by the effects of globalization on higher education and interpersonal communication.

When international student-athletes did not know others at their destination, there was a concerted and immediate effort by the coach and team members to integrate the newcomers. For example:

The following day after we arrived we were picked up by one of the head coach's assistants ... we were introduced to the team ... they were all really friendly. ... I can't think of anything more that they could have done. (male, 18)

As described by one interviewee, student-athletes were never without "a safety net" (male, 18), which contributed to their wellbeing and success on and off the sporting field. These micro and meso level experiences including the initial welcoming environment and support provided for the student-athletes was an indication of the ongoing support that could be expected.

\section{Ongoing Support: Authority Figures and Insulated Friendship Circles}

Ongoing support of international student-athletes and non-athletes also differed between the two groups. Non-athlete international students relied on friendship networks and international student services (ISSs), while the ongoing needs of international student-athletes were met through their immediate team community and the well-resourced athletics department. As explained by one student-athlete, "everything I need is done basically from . . . track-and-field" (female, 22).

A defining characteristic of the international student-athlete experience was the linking capital, which as shown in this study was gained through the central and ongoing support of their coach. As noted by one interviewee, coaches constitute "pretty well-known public figures" (male, 18). While there may be notable differences in pay and prestige, with variation by sport, gender, and race, NCAA coaches nonetheless occupy positions of influence on U.S. college campuses. For 
many interviewees in our study, their interaction with head coaches included daily conversations:

If I called him at 9 o'clock at night he'd be willing to talk to me. ... He'd come into his office on a weekend to help you out. I could openly talk to him about anything. ... That was immensely important. (female, 23)

Another commented, "I go into his office quite a bit . . . just to have a yarn" (male, 20). The coach represented both an institutional anchor and a guardian. For one student-athlete, her coach was a critical point of contact for her parents back home in Australia:

... my parents were communicating with [my coach] quite a lot and said, "make sure you look after her" ... so he knew that I was struggling. He'd bring me into his office once a week just for a meeting, and talk to me and make sure that everything was ok. ... I never felt alone, I felt upset and homesick, but I never felt like I didn't have anyone to talk to. (female, 23)

Coaches constituted directly accessible institutional ties, and were available to international student-athletes over both the short and long term. They provided the kinds of informal care expected by families and needed to ensure a successful education experience (Ranson, 2012). Furthermore, the approach of coaches appeared to cater to students who may be in unsupported circumstances and be considered "at risk" (Gershon, 2012, p. 12).

Although student-athletes in our sample were aware that meso level formal services for international students existed on campus, ISS were generally viewed as peripheral to their main support system. Some student-athlete interviewees relied only on the athletic department to take care of bureaucratic paperwork. For example, one student-athlete reported having her annual tax return done by an employee within the athletic department. Others navigated bureaucratic hurdles with the assistance of coaching staff. The privileged status of the athletic department also entitled international student-athletes to extra academic support:

You get an extra advisor. ... We also get group tutorial sessions ... [and] we get our textbooks pre-wrapped for us so we don't have to go wait in line at the textbook bookstore. (male, 19)

I think being a student-athlete, even though I was international, I was privileged a bit as a student because we had free tutoring services, psychology [services].... The availability of those services was more readily accessible for us. (female, 23)

In some cases, interviewees were helped by employees within the athletic department to reorganize their academic schedule when classes interfered with training and racing. The examples above demonstrate the inequities between the privileged student-athlete and other international students, whose support appeared to be more limited. More specifically, all student-athlete interviewees in this study received what was termed a "free ride," meaning $100 \%$ coverage of their tuition, health insurance, and living expenses such as accommodations and food. This 
advantage is in contrast to the circumstances of several non-athlete interviewees who described financial stress as a defining feature of their experience:

Because international students come here without any kind of financial aid or scholarship, the tuition in American dollars it's really expensive, a heavy burden for the family. A lot of students want to save money for their parents on housing and they try to live in the cheaper area, which is less safe. (Chinese, female, 21)

Non-athletes also had a different perspective of the ISS available on campus. While not necessarily making more use of ISSs, non-athletes were more likely than student-athletes to identify them and other generic student services as a primary source of support. For example: "I do know that at the back of my mind, that if anything happened I have the ISS. [But] I don't really feel like I need them for my security" (Israeli, female, 35). And: "I think [international students] first report to the campus Department of Safety. ... If I were a victim of a crime that would be the first place I'd turn to" (Chinese, female, 21). One non-athlete interviewee stated that for some international students the "first point of contact will be their friends" because they have a "fear of talking to anyone in administration or anyone American" (Polish, female, 23). This suggests that although international students experience strong bonding social capital via their ties with similarly situated students, they may not form strong or personal connections to institutionalized sources of support and authority.

The ongoing support provided demonstrated the benefits of the capital enjoyed by international student-athletes compared with non-athletes who were reliant on ISSs. The ISSs provided a fallback position that was rarely used by the international student-athletes. Not only did international student-athletes have the support of their coaches but they also benefited from greater financial support. These forms of capital meant they did not need to be part of the broader group of students competing for support and services. Indeed, the capital they enjoyed led to the development of strong social networks.

Putnam (2000) describes bonding and bridging capital as the internal and external ties of a group. Our study indicates that both forms of capital can be forged through social relations within a single community. The team environment provided international student-athletes with a network of both fellow athletes and American students, representing simultaneously local ties and "people who have things in common with you" (female, 23). In contrast with non-athletes, international studentathletes were much more likely to report strong social networks, which provided them with "a big family" (male, 20) in addition to other resources. Their accounts revealed that the value of these networks extended beyond the initial arrival period. Indeed, most international student-athletes reported spending most or all their social time with other student-athletes (female, 23):

We're pretty antisocial to be honest ... by the time you're training, going to classes, going to training again ... I don't really have time to do much else. ... There are a few people that you'll talk to in your classes if you're doing group assignments, but there's not really anyone I've made the effort to catch up with at another time. (female, 21) 
We train so much, there's probably 40 people ... most of my friends are definitely from the track team. (male, 21)

A similar tendency emerged in the accounts of non-athlete international students: "Usually there is a tendency of forming friends and hanging out with other international students much more so than with other American students just because we have that difference in common" (female, 23).

Indeed, university policies and particularly those related to housing repeatedly emerged as key to the formation of friendships across separate spheres. One studentathlete explained that his university had a dormitory policy to room student-athletes with non-athletes. He indicated that his "main circle of friends were those people in his dorm" (male, 19) who were not other student-athletes. Another student-athlete reported: "My freshmen year when we lived in dorms we were rooming next to people who weren't on teams, so I made quite a few friends that first year who were not athletes" (female, 20). Nonetheless, the international student-athletes tended to make friends with their teammates as interaction with other students, including other international students, required either conscious effort or structured interaction facilitated by university policies.

There was also evidence, however, that not all international student-athletes experienced strong social ties with their teammates. One student-athlete referred to a teammate who didn't speak English well and was "a bit of a loner" (male, 21). He also described "a few ... girls on the track team ... [who] definitely do congregate together." Similarly, although most non-athletes in our sample reported that they and other international students succeeded in forming support networks, they also observed exceptions:

Some international students may feel really alone, homesick, isolated from their environment. ... For example, one Chinese male, we didn't have any contact at all with him, also a Japanese girl ... they were basically ... coming back home, closing the door. (Turkish, male, 23)

Despite such heterogeneity, it was evident in this study that student-athletes overall experienced denser and more locally embedded social networks than nonathlete international students. Although this in many cases contributed to their isolation from the main student body, student-athletes appeared to feel more strongly supported and culturally comfortable during their sojourn than the non-athletes.

\section{DISCUSSION AND CONCLUSION}

Within the framework of higher education and sport, our focus on international student-athletes reveals that the centrality of NCAA sports in U.S. colleges ensured that international student-athletes were embraced by highly organized, high-status, and tightly woven networks of people and programmatic resources. International student-athletes were therefore given immediate access to a circle of friends that functioned as a "big family," with whom they often lived, trained, traveled, studied, and socialized. That is, they enjoyed privileged social networks (Potuto \& O'Hanlon, 2007). International student-athletes also benefited from their strong personal 
connections to people in positions of authority (particularly coaching staff) and their access to additional academic advising and other services. Being located within the athletic department structure meant they had resources to navigate the bureaucratic hurdles related to taxation and visas, as well as direct access to medical and counseling services.

At the same time, both athletes and non-athletes were often embedded in insulated friendship networks: Just as many international student-athletes described the athlete community they belonged to as "segregated" from other students, several international non-athlete students reported their friendship circles as consisting largely of other international students. This outcome supports an earlier finding by Umbach and colleagues (2006), who indicated that there was considerable overlap in the college experiences of student-athletes and non-athletes. These two social network patterns had distinct strengths and weaknesses. Importantly, the non-athlete group experienced an absence of the high-status figures and team camaraderie and friendships with American students that seemed to be important parts of the studentathlete experience.

Examples of the contrasting experiences of international student-athletes and non-athletes included the arrival experience, which has previously been described as a "critical moment" for international students (Forbes-Mewett, 2011; Yan \& Sendall, 2016) In contrast with the non-athletes in our study, the international student-athletes viewed this period very positively. Also, the support received after arrival and throughout their sojourn was thought to contribute to the success of the international student-athletes. This support contrasts markedly with previous studies of non-athlete international students in Australia, which found that they felt unsupported in the initial stages of their sojourn (Forbes-Mewett, 2011; Marginson et al., 2010). However, more positive views align in many ways with a previous marco level crosscountry comparative study, which indicated the US provided a "hand-holding" approach to all students, and particularly to international students (Forbes-Mewett et al., 2015). In the current study, there was demonstrated support provided upon arrival that appeared to be two-tiered and influenced by different institutional relationships. A case in point was being part of a team that provided support and advanced social capital in surroundings where students were not versed and required access to established resources. This process was further assisted by using social media to enable social capital through network formation, which reflects the impact of social media and globalization on higher education and interpersonal communication (Kalantzis \& Cope, 2012).

The international student-athletes in our study experienced linking capital that was accessible through the ongoing support of their coach, who typically held an influential position within the U.S. college structure (Fink, Pastore, \& Riemer, 2001). Daily interactions with head coaches were enabled through regular training sessions and meetings. The coaches provided informal care that served the international student-athletes and their families well (Ranson, 2012), and provided support for those deemed "at risk" (Gershon, 2012, p. 12). The findings also supported Putnam's (2000) description of bonding and bridging capital, these being the internal and external ties of a group. We found both these forms of capital were developed within 
community. That is, the team environment provided international student-athletes with networks involving fellow athletes and American students.

We suggest several possible interventions that may help administrators to address the social and institutional discrepancies between international athletes and nonathletes. These interventions build on earlier studies that have sought to address concerns about international students, but would also benefit domestic students by promoting their cross-cultural learning and international networks (Cho \& Yu, 2015; Forbes-Mewett et al., 2015; Luo \& Jamieson-Drake, 2013; Marginson et al., 2010). First, administrators could increase the heterogeneity of social interaction by requiring that dormitory living arrangements combine student-athletes, international students, and domestic students. Under current NCAA requirements, no institution can have a dormitory with more than $49 \%$ student-athletes. Our study suggests it may be beneficial to lower this percentage further, and that schools should establish similar arrangements for non-athlete international students. Second, administrators could facilitate the formation of different "teams" that need not necessarily be sport-related but which could create the level of social capital enjoyed by student-athletes, particularly if they are led by student support staff empowered with the authority to advocate for and negotiate on behalf of a manageable number of international students. Third, administrators should do more to strongly encourage international students to engage in an extracurricular activity on or off campus, a student club, or some other student-led organization for at least their first year. Universities could produce a list of recommended clubs or activities to ensure that international students are branching out beyond their existing networks of friends and acquaintances (see also Glass \& Gesing, 2018; Luo \& Jamieson-Drake, 2015). However, to succeed, such an initiative would require the fostering of a broader university culture that encourages inclusion, learning, and engagement.

Indeed, the challenge for administrators, particularly those working in ISSs, is that each intervention described above is associated with higher order changes in the existing structures and practices of higher education institutions. This challenge is not new in the context of international students in general; however, what is new is that the circumstances for international student-athletes in the US have highlighted a deficiency in support for the wider group of international students. As our research demonstrates, a critical institutional approach to the study of social capital offers explanatory power to education scholars seeking to link micro-level experiences and meso-level practices to macro-level institutional processes.

\section{REFERENCES}

Bale, J. (1991). The brawn drain: Foreign student-athletes in American universities. Urbana, IL: University of Illinois Press.

Bourdieu, P. (1986). The forms of capital. In J. Richardson (Ed.), Handbook of theory and research for the sociology of education (pp. 241-258). Ithaca: Greenwood Press.

Bowen, W. G., \& Levin, S. A. (2003). Reclaiming the game: College sports educational values. Princeton, NJ: Princeton University Press. 
British Council. (2012). The rise in student safety concerns. London: Education Intelligence.

Cho, J., \& Yu, H. (2015). Roles of university support for international students in the United States: Analysis of a systematic model of university identification, university support, and psychological well-being. Journal of Studies in International Education, 19, 11-27.

Clopton, A. (2010). The impact of intercollegiate athletic participation upon sense of community across multiple levels of competition. International Journal of Sport Management, 12(3), 440-456.

Coleman, J. S. (1988). Social capital in the creation of human capital. American Journal of Sociology, 94(Suppl.), S95-S120.

Comeaux, E., \& Harrison, K. C. (2011). A conceptual model of academic success for student-athletes. Educational Researcher, 40(5), 235-245.

Das, R. (2004). Social capital and poverty of the wage-labour class: Problems with social capital theory. Transactions of the Institute of British Geographers, 29(1), $27-45$.

Elling, A., \& Claringbould, I. (2005). Mechanism of inclusion and exclusion in the Dutch sports landscape: Who can and wants to belong? Sociology of Sport Journal, 22(4), 498-515.

Etzel, E., Watson, J. C., Visek, A. J., \& Maniar, S. D. (2006). Understanding and promoting college student-athlete health: Essential issues for student affairs professionals. NASPA Journal, 43(3), 518-546.

Ferris, E., Finster, M., \& McDonald, D. (2004). Academic fit for student-athletes: An analysis of NCAA division I-A graduation rates. Research in Higher Education, $45,555-575$.

Field, J. (2003). Social capital. London: Routledge.

Fink, J., Pastore, D., \& Riemer, H. (2001). Do differences make a difference? Managing diversity in Division IA intercollegiate athletics. Journal of Sport Management, 15(1), 10-50.

Forbes-Mewett, H. (2011). International education preparation: Minimising risk and furthering security. International Journal of Contemporary Sociology, 48(1), 6192.

Forbes-Mewett, H., Marginson, M., Nyland, C., Ramia, G., \& Sawir, E. (2009). Australian university international student finances. Higher Education Policy, 22(2), 141-161.

Forbes-Mewett, H., McCulloch, J., \& Nyland, C. (2015). International students and crime. Houndmills: Palgrave Macmillan.

Forbes-Mewett, H., \& Nyland, C. (2008). Cultural diversity, relocation and the security of international students at an internationalised university. Journal of Studies in International Education, 12(2), 181-203.

Forbes-Mewett, H., \& Nyland, C. (2013). Funding international student services: Tension and power in the university. Higher Education, 65(2), 181-192.

Forbes-Mewett, H., \& Sawyer, A.M. (2016). International students and mental health. Journal of International Students, 6(3), 661-677.

Gayles, J. L. (2009). The student athlete experience. New Directions for Institutional Research, 144(Winter), 33-41. 
Gershon, W. S. (2012). Troubling notions of risk: Dissensus, dissonance, and making sense of students and learning. Critical Studies in Education, 53(3), 361-373.

Glass, C. R., \& Gesing, P. (2018). The development of social capital through international students' involvement in campus organizations. Journal of International Students, 8(3), 1274-1292.

Harrison, C., Stone, J., Shapiro, J., Yee., S., Boyd, J., \& Rullan, V. (2009). The role of gender identities and stereotype salience with the academic performance of male and female college athletes. Journal of Sport and Social Issues, 33(1), 7896.

Hastie, B., \& Rimmington, D. (2014). “200 years of white affirmative action”: White privilege discourse in discussions of racial inequality. Discourse \& Society, 25(2), 186-204.

Hendrickson, B., Rosen, D., \& Aune, R. K. (2011). An analysis of friendship networks, social connectedness, homesickness, and satisfaction levels of international students. International Journal of Intercultural Relations, 35(3), 281-295.

Jacobs, D., \& Tillie, J. (2004). Introduction: Social capital and political integration of migrants. Journal of Ethnic and Migration Studies, 30(3), 419-427.

Kalantzis, M., \& Cope, B (2012). New learning: Elements of a science of education. Cambridge: Cambridge University Press.

Lee, J., \& Rice, C. (2007). Welcome to America? International student perceptions of discrimination. Higher Education, 53(3), 381-409.

Lewis, A. E. (2004). "What group?" Studying whites and whiteness in the era of "color-blindness." Sociological Theory, 22(4), 623-646.

Lubker, J. R., \& Etzel, E. F. (2007). College adjustment experiences of first-year students: Disengaged athletes, nonathletes, and current varsity athletes. NASPA Journal, 44(3), 457-480.

Luo, J., \& Jamieson-Drake, D. (2013). Examining the educational benefits of interacting with international students. Journal of International Students, 3(1), 85-101.

Luo, J., \& Jamieson-Drake, D. (2015). Predictors of study abroad intent, participation, and college outcomes. Research in Higher Education, 56(1), 29-56.

Marginson, S., Nyland, C., Sawir, E., \& Forbes-Mewett, H. (2010). International student security. Cambridge: Cambridge University Press.

Neri, F., \& Ville, S. (2008). Social capital renewal and the academic performance of international students in Australia. Journal of Socio-Economics, 37(4), 15151538.

Parry, G., McLeod, J., Hockings, C., \& Kenway, J. (2011). A conversation on mobility, aspiration and voice. Critical Studies in Education, 52(2), 207-212.

Perks, T. (2007). Does sport foster social capital? The contribution of sport to a lifestyle of community participation. Sociology of Sport Journal, 24(4), 378-401.

Pierce, D., Popp, N., \& Meadows, B. (2011). Qualitative analysis of international student-athlete perspectives on recruitment and transitioning into American college sport. The Sport Journal, 14(1). Accessed from: http://thesportjournal.org/article/qualitative-analysis-of-international-student- 
athlete-perspectives-on-recruitment-and-transitioning-into-american-collegesport/

Popp, N., Love, A. W., Kim, S., \& Hums, M. (2010). Cross-cultural adjustments and international collegiate athletes. Journal of Intercollegiate Sport, 3, 163-181.

Portes, A. (2000). The two meanings of social capital. Sociological Forum, 15(1), 112.

Potuto, J. R., \& O’Hanlon, J. (2007). National study of student-athletes regarding their experiences as college students. College Student Journal, 41(4), 947-966.

Putnam, R. D (2000). Bowling alone: The collapse and revival of American community. New York: Simon \& Schuster.

Ranson, S. (2012). Schools and civil society: Corporate and community governance. Critical Studies in Education, 53(1), 29-45.

Ridinger, L., \& Pastore, D. (2000). International student-athlete adjustment to college: A preliminary analysis. NACADA Journal, 20(1), 33-41.

Rienties, B., \& Nolan, E. M. (2014). Understanding friendship and learning networks of international and host students using longitudinal Social Network Analysis. International Journal of Intercultural Relations, 41, 165-180.

Rose-Redwood, C. R., \& Rose-Redwood, R. S. (2013). Self-segregation or global mixing? Social interactions and the international student experience. Journal of College Student Development, 54(4), 413-429.

Schuller, T., Baron, S., \& Field, J. (2000). Social capital: A review and critique. In S. Baron, J. Field, \& T. Schuller (Eds.), Social capital: Critical perspectives (pp. 1-38). Oxford: Oxford University Press.

Sprague, J. (2005). Feminist methodologies for critical researchers. Walnut Creek, CA: AltaMira Press.

Strauss, A., \& Corbin, J. (1990). Basics of qualitative research: Grounded theory procedures and techniques. Boston: Kluwer Academic.

Thelin, J. (1994). Games colleges play: Scandal and reform in intercollegiate athletics. Baltimore: John Hopkins University Press.

Umbach, P., Palmer, M., Kuh, G., \& Hannah, S. (2006). Intercollegiate athletics and effective educational practices: Winning combination or losing effort? Research in Higher Education, 47(6), 709-733.

Ward, C., Bochner, S., \& Furnham, A. (2001). The psychology of culture shock (2nd ed.). East Sussex: Routledge.

Wolf-Wendel, L., Toma, J., \& Morphew, C. (2001). There's no "I" in "team": Lessons from athletics in community building. The Review of Higher Education, 24(4), 369-396.

Woolcock, M., \& Narayan, D. (2000). Social capital: Implications for development theory, research and policy. World Bank Research Observer, 15(2), 225-249.

Yan, Z., \& Sendall, P. (2016). First year experience: How we can better assist international students in higher education. Journal of International Students, $6(1), 35-51$.

Yee, A. (2016). The unwritten rules of engagement: Social class differences in undergraduates' academic strategies. The Journal of Higher Education, 87(6), 831-858. 
HELEN FORBES-MEWETT, PhD, is Senior Lecturer in the School of Social Sciences at Monash University. Her major research interests lie in the areas of human security, international education, international student safety and security, migration, cultural diversity and social cohesion. Email: helen.forbesmewett@ monash.edu

MADELEINE PAPE, PhD, is a Postdoctoral Fellow in the Science and Human Culture program at Northwestern University. Her current research focuses on gendered organizational change and feminist debates surrounding the inclusion of sex and gender in biomedical research and the regulation of female eligibility in international sport. Email: madeleine.pape@northwestern.edu 